\title{
Clinical analysis of tracheobronchial foreign body aspiration in children: a focus on external and intrinsic factors
}

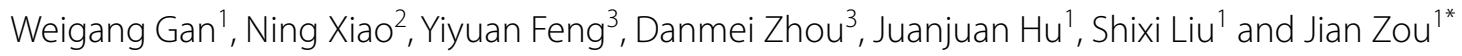

\begin{abstract}
Background: Tracheobronchial foreign body aspiration (TFBA) is a critical disease in children and is extremely dangerous, even life-threatening. The factors affecting the occurrence and prognosis of TFBA are complex. The purpose of this study is to examine the external and intrinsic factors affecting clinical features of TFBA in West China and propose potential effective intervention measures.

Methods: We retrospectively analyzed the clinical data of pediatric patients diagnosed with TFBA with foreign bodies (FBs) removed by rigid bronchoscopy under general anesthesia at the otolaryngology department from December 2017 to November 2018. The data included age, sex, clinical symptoms, type and location of FB, guardians, prehospital duration and residence of these pediatric patients.

Results: The ratio of males (72) to females (53) was 1.4:1. Children aged from 1 to 3 years accounted for 76\% (95/125) of patients. Cough, continuous fever and dyspnea were the primary symptoms. The right primary bronchus was the most common location of FB detection by rigid bronchoscopy (67 cases, 53.6\%). Organic FBs were most common in our study. Guardians of patients significantly differed in the rural (parents 16, grandparents 31 ) and urban (parents 52, grandparents 26) groups $\left(x^{2}=12.583, p=0.000\right)$. More children in the rural group than in the urban group had a treatment delay longer than $72 \mathrm{~h}$. More children in the group with no history of FB aspiration (12, 25\%) than in the group with prior FB aspiration had a treatment delay longer than $72 \mathrm{~h}$.

Conclusion: Pediatric TFBA is a common emergency in otolaryngology. Age, sex, tracheobronchial anatomy and other physiological elements were defined as intrinsic factors, while guardians, residence, FB species and prehospital time were defined as external factors of TFBA. External and intrinsic factors both influence the occurrence and progression of TFBA. It is extremely important to take effective measures to control external factors, which can decrease morbidity and mortality.
\end{abstract}

Keywords: Tracheobronchial foreign body aspiration, Rigid bronchoscopy, Guardians, External factors, Intrinsic factors

*Correspondence: zoujian@wchscu.cn

${ }^{1}$ Department of Otorhinolaryngology-Head and Neck Surgery, West China Hospital, West China School of Medicine, Sichuan University, Chengdu, Sichuan, People's Republic of China

Full list of author information is available at the end of the article

\section{Background}

Pediatric tracheobronchial foreign body aspiration (TFBA) is the most hazardous and most common emergency among respiratory tract diseases; it not only initiates infection but also causes obstructive asphyxia or spasmodic asphyxia [1]. The 2008 statistics from the National Safety Council (NSC) revealed that over 17 thousand pediatric patients in the United States who 
were younger than 14 years presented to the emergency department, and approximately 220 patients eventually died due to TFBA in that year alone [2]. Hence, it is extremely important for patients to be examined by an emergency medicine specialist in a timely manner and receive professional treatment if they are suffering from TFBA. However, when and whether children are taken to the hospital depends on multiple factors related to their guardians, such as economic status, geographical location, education degree and disease cognition. West China is characterized by mountainous areas that have less developed infrastructure and economic conditions than East China. We analyzed the clinical data to determine the external and intrinsic factors that affect the clinical features of TFBA in this area. The external factors were related to the living environment, and the intrinsic factors referred to physiological factors such as age and tracheobronchial anatomy.

\section{Methods}

This study was approved by the Institutional Review Board of the West China Hospital and performed at the West China Hospital National Diagnosis and Treatment Center of West China for Emergency and Critical Disease (NO. 2017-448). We retrospectively analyzed the clinical data of pediatric patients diagnosed with TFBA with foreign bodies (FBs) removed by rigid bronchoscopy under general anesthesia at the otolaryngology department from December 2017 to November 2018. Owing to the development of the respiratory tract and physiological function, older children manifest more potential safety risks than infants do. Thus, we enrolled children younger than 7 years who had not entered the first grade of primary school and who had been diagnosed with TFBA by computed tomography (CT) scan, auscultation, symptoms or history of FB aspiration, which was further verified by rigid bronchoscopy. The clinical data collected consisted of demographics (age distribution, sex), residence (rural, urban), guardians (parents, grandparents), aspiration history (witnessed or not, length of time before treatment), symptoms, bronchoscopic findings and types of FBs. Statistically, qualitative data or proportions were analyzed by Fisher's exact test or Pearson's $\chi^{2}$ test. In our study, qualitative data included the sample quantity in subgroups divided according to demographic factors (age distribution, sex), residence (rural, urban), guardians (parents, grandparents), aspiration history (witnessed or not, length of time before treatment) and types of FBs.

SPSS software (version 22.0, IBM, Chicago, USA) was used to conduct the statistical analysis. A value of $p<0.05$ (two tailed) was considered statistically significant.

\section{Results}

\section{Patient demographics}

In total, 125 pediatric patients diagnosed with TFBA and treated by rigid bronchoscopy under general anesthesia at the otolaryngology department of the West China Hospital from December 2017 to November 2018 were enrolled in our study. The ratio of males (72) to females (53) was 1.4:1. The age distribution ranged from 7 months to 6 years, with a mean age of $2.02 \pm 1.13$ years; children younger than 1 year accounted for $11.2 \%(14 / 125)$, those aged 1 to 3 years accounted for $76 \%(95 / 125)$, and those older than 3 years accounted for $12.8 \%(16 / 125)$ of patients (Table 1). Among children younger than 1 year old, the patients included 7 males and 7 females, and the FBs included 3 cases involving peanuts, 8 cases involving seeds, 2 cases involving sarcocarps, and 1 case involving rice. The locations included the right primary bronchus in 7 cases, left primary bronchus in 6 cases, and trachea in 1 case.

\section{Clinical manifestations}

Regarding clinical symptoms, 114 patients suffered from cough as a major symptom (91.2\%), 72 patients suffered from heaving as a major discomfort (57.6\%), 56 patients suffered from continuous fever (44.8\%), 48 children had dyspnea as the most distressing symptom (38.4\%), and 46 pediatric patients exhibited obvious wheezing (36.8\%) (Table 1). Regarding the location of the FBs, the right primary bronchus was the most common position involved, with FBs detected by rigid bronchoscopy in 67 cases (53.6\%), followed by the left primary bronchus $(49 / 125$, $39.2 \%)$ and trachea $(9 / 125,7.2 \%)$. The FB was successfully removed in 125 cases, and the location of the FB was consistent with the preoperative imaging examination (Table 1). Position variance of FBs from the right bronchus to the left bronchus was observed in 3 cases during the operation.

Types of foreign bodies.

Diverse types of FBs were documented in our study. In decreasing order of occurrence, the FBs included peanuts $(51,40.8 \%)$, sunflower seeds $(32,25.6 \%, 18$ cases with only the shell and 14 cases with both the shell and the seed), walnuts $(23,18.4 \%)$, rice or noodles $(13,10.4 \%)$, sarcocarps $(4,3.2 \%)$, and metal and plastics $(0.8 \%)$ (Table 2).

\section{Prehospital elements}

In terms of residence, 47 patients lived in rural areas (37.6\%), while 78 patients lived in urban areas (62.4\%). Regarding guardians, 68 children were cared for daily by parents $(54.4 \%)$; however, 57 were cared for by grandparents (45.6\%). It was inquired of all patients whether the FB had been inhaled while eating or playing with 
Table 1 Demographics and clinical characteristics of the study cohorts

\begin{tabular}{|c|c|c|}
\hline & \multicolumn{2}{|c|}{ Quantity } \\
\hline & No & Proportion (\%) \\
\hline \multicolumn{3}{|l|}{ Gender } \\
\hline Male & 72 & 57.6 \\
\hline Female & 53 & 42.4 \\
\hline \multicolumn{3}{|l|}{ Age (month) } \\
\hline$\leq 12$ & 14 & 11.2 \\
\hline $13-36$ & 95 & 76.0 \\
\hline$>36$ & 16 & 12.8 \\
\hline \multicolumn{3}{|l|}{ Prehospital time (h) } \\
\hline$<24$ & 72 & 57.6 \\
\hline $24-72$ & 36 & 28.8 \\
\hline$\geq 72$ & 17 & 13.6 \\
\hline \multicolumn{3}{|l|}{ Types of foreign bodies } \\
\hline Peanuts & 51 & 40.8 \\
\hline Sunflower seeds & 32 & 25.6 \\
\hline Walnut seeds & 23 & 18.4 \\
\hline Rice and noodles & 13 & 10.4 \\
\hline Sarcocarp & 4 & 3.2 \\
\hline Metal & 1 & 0.8 \\
\hline Plastics & 1 & 0.8 \\
\hline \multicolumn{3}{|l|}{ Foreign body locations } \\
\hline Left primary bronchus & 49 & 39.2 \\
\hline Right primary bronchus & 67 & 53.6 \\
\hline Trachea & 9 & 7.2 \\
\hline \multicolumn{3}{|l|}{ Clinical symptoms } \\
\hline Coughing & 114 & 91.2 \\
\hline Heaving & 72 & 57.6 \\
\hline Fever & 56 & 44.8 \\
\hline Dyspnea & 48 & 38.4 \\
\hline Wheezing & 46 & 36.8 \\
\hline \multicolumn{3}{|l|}{ Residences } \\
\hline Rural & 47 & 37.6 \\
\hline Urban & 78 & 62.4 \\
\hline \multicolumn{3}{|l|}{ Guardians } \\
\hline Parents & 68 & 54.4 \\
\hline Grand parents & 57 & 45.6 \\
\hline
\end{tabular}

the object in the child's mouth. The longest prehospital time after FB aspiration was 17 days, and the shortest prehospital time was $0.5 \mathrm{~h} ; 72$ patients $(57.6 \%)$ were brought to the hospital within one day, 36 patients were brought to the hospital between 1 and 3 days (28.8\%), and 17 patients were brought to the hospital after more than 3 days (13.6\%) (Table 1$)$.

Among urban and rural children, the most common FBs were peanuts (31 vs 20 ), sunflower seeds ( 20 vs 12 ), and walnuts (15 vs 8 ), with no significant difference between groups $\left(\chi^{2}=2.580, p=0.946>0.05\right)$. The sex ratio of the rural (40 females, 19 males) and urban (32 females, 34 males) groups was not significantly different $\left(x^{2}=0.934, p=0.362\right)$. The guardians of patients in the rural (parents 16, grandparents 31) and urban (parents 52 , grandparents 26 ) groups were significantly different $\left(x^{2}=12.583, p=0.000\right)$. The prehospital times after FB aspiration in the rural $(<24 \mathrm{~h}, 32 ; 24-72 \mathrm{~h}, 7 ; \geq 72 \mathrm{~h}, 8)$ and urban ( $<24 \mathrm{~h}, 40 ; 24-72 \mathrm{~h}, 29 ; \geq 72 \mathrm{~h}, 9)$ groups were significantly different $\left(\chi^{2}=7.144, p=0.028\right)$. Although most patients in both groups were taken to the doctor within $24 \mathrm{~h}$, more children were treated from 24 to $72 \mathrm{~h}$ in the urban group than in the rural group (29/78 vs $7 / 47$ ), and fewer children were treated after more than $72 \mathrm{~h}$ in the urban group than in the rural group (9/78 vs 8/47) (Table 3).

When pediatric patients were divided into two groups according to prior FB aspiration, a significant difference was observed between the two groups in the time until a doctor was consulted $\left(x^{2}=11.573, p=0.003\right)$. Although most patients in both groups were treated at a pediatric clinic or emergency room within $24 \mathrm{~h}$, more children in the group without prior FB aspiration (12, 25\%) were treated after more than $72 \mathrm{~h}$ than in the group with previous FB aspiration $(5,6.5 \%)$ (Table 4). After 1 year of follow-up, pediatric patients with TFBA in our group had no complications, including pulmonary dysfunction.

\section{Discussion}

Pediatric TFBA refers to children who suffer from aspiration of a variety of objects by mistake while crying, smiling or yelling. It is very important to consult specialists for professional aid immediately after aspiration occurs or to avoid it from the very beginning. In our opinion, the occurrence of TFBA is influenced by several external and intrinsic factors. Here, we aim to discuss these factors and search for potentially effective measures corresponding to these factors.

Physiological elements of children were defined as intrinsic factors, including age, sex, tracheobronchial anatomy and symptoms. Accordingly, elements irrelevant to children were defined as external factors, including guardians, residence, type of FB and prehospital time.

Owing to both the laryngeal protective function and masticatory function development, TFBA usually occurs in young children, especially those less than 3 years old [3]. In our study, the age distribution of pediatric patients was mostly from 1 to 3 years, coinciding with Arias's findings from the National Center for Health Statistics [4]. In addition, there were 72 boys and 53 girls enrolled in our study, and the male-female ratio was 1.36, similar to that in Maha's study [5]. As is well known, infants attempt to explore the world with 
Table 2 Composition ratio of the types of foreign bodies between urban and rural children (n,\%)

\begin{tabular}{|c|c|c|c|c|c|c|}
\hline \multirow[b]{2}{*}{ Types of fbs } & \multicolumn{2}{|c|}{ Urban } & \multicolumn{2}{|c|}{ Rural } & \multicolumn{2}{|c|}{ Count } \\
\hline & $\mathrm{n}$ & $\%$ & $\mathrm{n}$ & $\%$ & $n$ & $\%$ \\
\hline Peanuts & 31 & 39.8 & 20 & 42.6 & 51 & 40.8 \\
\hline Sunflower seeds & 20 & 25.6 & 12 & 25.6 & 32 & 25.6 \\
\hline Walnuts & 15 & 19.2 & 8 & 17.0 & 23 & 18.4 \\
\hline Rice and noodle & 8 & 10.3 & 5 & 10.6 & 13 & 10.4 \\
\hline Sarcocarp & 3 & 3.8 & 1 & 2.1 & 4 & 3.2 \\
\hline Metal & 1 & 1.3 & 0 & 0 & 1 & 0.8 \\
\hline Plastics & 0 & 0 & 1 & 2.1 & 1 & 0.8 \\
\hline Count & 78 & 100 & 47 & 100 & 125 & 100 \\
\hline
\end{tabular}

$x^{2}=2.580, p=0.946>0.05$

Table 3 Differences in gender, guardians and prehospital time between the two groups (n)

\begin{tabular}{|c|c|c|c|c|c|c|c|}
\hline \multirow[b]{2}{*}{ Residence } & \multicolumn{2}{|l|}{ Gender } & \multicolumn{2}{|c|}{ Caregivers } & \multicolumn{3}{|c|}{ Prehospital time (h) } \\
\hline & Female & Male & Parents & Grandparents & $<24$ & $24-72$ & $\geq 72$ \\
\hline Urban & 32 & 19 & 52 & 26 & 40 & 29 & 9 \\
\hline Rural & 40 & 34 & 16 & 31 & 32 & 7 & 8 \\
\hline Count & 72 & 53 & 68 & 57 & 72 & 36 & 17 \\
\hline$x^{2}$ & 0.934 & & 12.583 & & 7.144 & & \\
\hline$P$ & 0.362 & & 0.000 & & $0.028^{*}$ & & \\
\hline
\end{tabular}

Table 4 Prehospital time after FB aspiration between two groups (n, \%)

\begin{tabular}{|c|c|c|c|c|c|c|}
\hline \multirow{2}{*}{$\begin{array}{l}\text { Prehospital time(h) } \\
<24\end{array}$} & \multicolumn{2}{|c|}{ With history } & \multicolumn{2}{|c|}{ Without history } & \multicolumn{2}{|c|}{ Count } \\
\hline & 52 & 67.5 & 20 & 41.7 & 72 & 57.6 \\
\hline $24-72$ & 20 & 26.0 & 16 & 33.3 & 36 & 28.8 \\
\hline$\geq 72$ & 5 & 6.5 & 12 & 25.0 & 17 & 13.6 \\
\hline Count & 77 & 100 & 48 & 100 & 125 & 100 \\
\hline
\end{tabular}

$x^{2}=11.573, p=0.003<0.05$, History $=$ history of $\mathrm{FB}$ aspiration

their tongues and mouths, and boys typically show stronger curiosity and relative hyperactivity compared to girls in daily life. Therefore, we must repeatedly emphasize to guardians that infants should not be permitted to eat nuts. It is best to put nuts and tiny objects out of children's sight and reach.

In regard to bronchial anatomy, which affects the movement track of FBs, the right primary bronchus is steeper and wider than the left side [6]. As a result, the occurrence rate of right bronchial FBs is higher than that of other types [7]. FBs in our study were mostly located in the right bronchus, followed by the left bronchus and trachea. Tracheal FBs are fatal, despite a low incidence of morbidity [8]. In some cases, FBs migrated after violent coughing or patting of the back.
Position variance of FBs from the right bronchus to the left bronchus was observed in 3 patients during the operation.

Cough, heaving, fever, and dyspnea were the four symptoms of highest incidence in our patients. The symptoms mainly depended upon the prehospital duration and the type of FB. Tan et al. concluded that nuts and seeds, with some geographic and seasonal variations, were the most common FBs [9]. In our group, most of the FBs were organic objects, such as peanuts, sunflower seeds and walnuts, which produce unsaturated fatty acid and thus promote inflammation of the airway mucosa.

Most of western China is mountainous, and rural and urban districts are different in terms of infrastructure and economic conditions. We regard the regional difference 
as an external factor of TFBA. When the patients were divided into two groups according to their residence, we found a significant difference in the guardians and medical history time but not in the sex of patients or the composition of the types of FBs.

Parents of pediatric patients with TFBA are younger than their grandparents, and the parents are also generally more educated than the grandparents. Guardians mostly included grandparents in rural areas because some parents in rural areas migrated to urban districts to search for employment, leaving children to be cared for by the grandparents. However, some parents also took children with them into urban districts, leading to fewer children living in villages and fewer patients with TFBA from rural areas. In our study, more pediatric patients were from urban areas, and more ill children were cared for by grandparents in rural areas. Therefore, in addition to providing information for parents, we must also educate grandparents, especially in rural families.

Administering TFBA therapy as soon as possible upon arrival at the hospital is key to timely diagnosis and surgery [8]. However, Foltran et al. found that approximately $40 \%$ of patients received delayed diagnosis and treatment [10], and more than $72 \mathrm{~h}$ of prehospital time was considered to potentially increase the risk of complications such as pneumonia, atelectasis, pneumorrhachis, pneumothorax, subcutaneous emphysema and pneumomediastinum [11].

When we focused on the medical history time, significant differences were found between children with or without a history of FB aspiration. A total of $67.5 \%$ of pediatric patients with a history of FB aspiration were immediately dealt within $24 \mathrm{~h}$, while $58.3 \%$ of patients who had no explicit medical history were treated after $24 \mathrm{~h}$. Meanwhile, children living in different districts also showed differences in prehospital time. Although most patients in both groups were taken to the doctor within $24 \mathrm{~h}$, more children were not treated for over $72 \mathrm{~h}$ in the rural group than in the urban group. Guardians in rural areas were mostly grandparents, who possibly spend inadequate time caring for children and showed a lack of understanding about cognition of TFBA. Along with distance from medical centers or competent hospitals, the type of guardian was also associated with delayed diagnosis or therapy.

As a result, it is crucial for the guardian to be aware of the danger of TFBA, which could reduce its incidence and prevent medical delay.

\section{Conclusion}

Pediatric TFBA is a common emergency in otolaryngology. Age, sex, tracheobronchial anatomy and other physiological elements were defined as intrinsic factors, while guardians, residence, type of $\mathrm{FB}$ and prehospital time were defined as external factors of TFBA. External and intrinsic factors both influence the occurrence and progression of TFBA. It is very important to take effective measures to control external factors, which can decrease morbidity and mortality.

\section{Abbreviations}

FB: Foreign body; TFBA: Tracheobronchial foreign body aspiration; NSC: National Safety Council; CT: Computed tomography.

\section{Acknowledgements}

The authors thank the entire staff of the participating departments for their expert assistance and the American Journal Experts (AJE) for the professional language editing.

\section{Authors' contributions}

WG and NX were responsible for the data and sample collection; YF and JH were responsible for manuscript writing; DZ was responsible for data analysis; $\mathrm{SL}$ and JZ were responsible for the study design and paper revision. All authors have read and approved the manuscript.

\section{Funding}

This work was supported by grants to Weigang Gan from the Nanchong Social Science Research 13th Five-Year Plan Project (NC16B040) and the Science and Technology Strategic Cooperation Project of Nanchong City and NSMC (18SXHZ0118). The funding body did not take part in the design of the study, collection and interpretation of data and in writing the manuscript.

\section{Availability of data and materials}

The dataset used and/or analyzed during the current study is available from the corresponding author on reasonable request.

Ethics approval and consent to participate

This study was in accordance with the Declaration of Helsinki and has been approved by the ethics committee of West China Hospital, Sichuan University.

Consent for publication

Not applicable.

\section{Competing interests}

The authors declare that they have no competing interests.

\section{Author details}

${ }^{1}$ Department of Otorhinolaryngology-Head and Neck Surgery, West China Hospital, West China School of Medicine, Sichuan University, Chengdu, Sichuan, People's Republic of China. ${ }^{2}$ Health Management Center, Sichuan Provincial People's Hospital, Chengdu, Sichuan, People's Republic of China.

${ }^{3}$ Department of Otorhinolaryngology-Head and Neck Surgery, Qianwei

People's Hospital, Sichuan 614400 Leshan, People's Republic of China.

Received: 10 August 2020 Accepted: 3 February 2021

Published online: 03 March 2021

\section{References}

1. Subspecialty Group of Pediatrics SoOH Neck Surgery CMA. Experts consensus on diagnosis and treatment of tracheobronchial foreign bodies in children. Zhonghua er bi yan hou tou jing wai ke za zhi Chin J Otorhinolaryngol Head Neck Surg. 2018;53(5):325-38.

2. Sheehan CC, Lopez J, Elmaraghy CA. Low rate of positive bronchoscopy for suspected foreign body aspiration in infants. Int J Pediatr Otorhinolaryngol. 2018;104:72-5.

3. Rodriguez H, Passali GC, Gregori D, Chinski A, Tiscornia C, Botto H, Nieto M, Zanetta A, Passali D, Cuestas G. Management of foreign bodies in the 
airway and oesophagus. Int J Pediatr Otorhinolaryngol. 2012;76(Suppl 1):S84-91.

4. Arias $\mathrm{E}$, Heron $\mathrm{M}$, Tejada-Vera B. United States life tables eliminating certain causes of death, 1999-2001. Natl Vital Statist Rep . 2013;61 (9):1-128.

5. Mohammad M, Saleem M, Mahseeri M, Alabdallat I, Alomari A, Za'atreh A, Qudaisat I, Shudifat A, Nasri Alzoubi M. Foreign body aspiration in children: A study of children who lived or died following aspiration. Int J Pediatr Otorhinolaryngol. 2017;98:29-31.

6. Gilyoma JM, Chalya PL. Endoscopic procedures for removal of foreign bodies of the aerodigestive tract: the Bugando Medical Centre experience. BMC Ear Nose Throat Disord. 2011;11:2.

7. Boufersaoui A, Smati L, Benhalla KN, Boukari R, Smail S, Anik K, Aouameur R, Chaouche H, Baghriche M. Foreign body aspiration in children: experience from 2624 patients. Int J Pediatr Otorhinolaryngol. 2013;77(10):1683-8.

8. Woo SH, Park JJ, Kwon M, Ryu JS, Kim JP. Tracheobronchial foreign body removal in infants who had very small airways: a prospective clinical trial. Clin Respir J. 2018;12(2):738-45.
9. Tan HK, Brown K, McGill T, Kenna MA, Lund DP, Healy GB. Airway foreign bodies (FB): a 10-year review. Int J Pediatr Otorhinolaryngol. 2000;56(2):91-9.

10. Foltran F, Ballali S, Passali FM, Kern E, Morra B, Passali GC, Berchialla P, Lauriello M, Gregori D. Foreign bodies in the airways: a meta-analysis of published papers. Int J Pediatr Otorhinolaryngol. 2012;76(Suppl 1):S12-19.

11. Chen $X$, Zhang C. Foreign body aspiration in children: Focus on the impact of delayed treatment. Int J Pediatr Otorhinolaryngol. 2017;96:111-5

\section{Publisher's Note}

Springer Nature remains neutral with regard to jurisdictional claims in published maps and institutional affiliations.
Ready to submit your research? Choose BMC and benefit from:

- fast, convenient online submission

- thorough peer review by experienced researchers in your field

- rapid publication on acceptance

- support for research data, including large and complex data types

- gold Open Access which fosters wider collaboration and increased citations

- maximum visibility for your research: over $100 \mathrm{M}$ website views per year

At BMC, research is always in progress.

Learn more biomedcentral.com/submissions 